\title{
Simultaneous determination of notoginsenoside R1 and ginsenosides Rg1, Re, Rb1 in dietary supplements by HPLC-DAD
}

\author{
Dam Thi Thu ${ }^{1^{*}}$, Nguyen Thi Kieu Anh ${ }^{2}$, Nguyen Thi Thanh Phuong \\ Nguyen Thi Hong Hanh ${ }^{1}$, Nguyen Thanh Đat ${ }^{1}$ \\ ${ }^{1}$ Hanoi Drugs, Cosmetics, Food Quality Control Center, Hanoi, Vietnam \\ ${ }^{2}$ Hanoi University of Pharmacy, Hanoi, Vietnam
}

(Received: 02/03/2021; Accepted: 27/04/2021)

\section{Abstract}

A method using solid phase extraction (SPE) and high performance liquid chromatography with diode array detector (HPLC-DAD) has been optimized for the simultaneous determination of notoginsenoside R1 and three ginsenosides Rg1, Re, Rb1 in solid, oil, and liquid dietary supplements. The substances were separated by an InertSustain C18 column $(250 \mathrm{~mm} \times 4.6 \mathrm{~mm}$ i.d.; particle size $5 \mu \mathrm{m}$ ) with a gradient program composed of acetonitrile and water. Linearities were in the range of $4.0-400 \mu \mathrm{g} / \mathrm{mL}$ with the coefficients of determination were more than 0.999. The limits of detection and limits of quantitation were $2.13-6.89 \mu \mathrm{g} / \mathrm{g}$ and $7.11-22.98$ $\mu \mathrm{g} / \mathrm{g}$, respectively. The recovery values of the compounds were in the range of $87.2-103.5 \%$. The precision study showed the intra-day relative standard deviation (RSD) of $1.41-2.91 \%$, and inter-day RSD of 1.87 - 4.85\%, which meet the AOAC International requirements. The method was applied to determine the content of notoginsenoside R1, ginsenoside Rg1, ginsenoside Re, and ginsenoside Rb1 in 20 dietary supplement samples containing Ginseng and Pseudoginseng. HPLC.

Keyword: notoginsenosid, ginsenoside Rg1, ginsenoside Re, ginsenoside Rb1, supplements,

\section{INTRODUCTION}

Recently, the demand use of traditional medicine and health supplement derived from natural herbal has been growing. Rare medicinal herbs such as Ginseng (Panax ginseng) and Pseudoginseng (Panax pseudoginseng) that have many preventive and therapeutic effects have become potential sources of raw materials for these products. Currently, these products are being sold in many pharmacies, drug stores, supermarkets, even online sales, and many of them come from unknown origins. The quality of many health supplement products are not well controlled, making it difficult for consumers to choose effective products. On the other hand, Ginseng and Pseudoginseng are medicinal herbs that have many species and are often counterfeited in the market [1].

There have been many studies proving that ginsenoside $\mathrm{Rg} 1(\mathrm{Rg} 1)$, ginsenoside $\mathrm{Rb} 1(\mathrm{Rb} 1)$, ginsenoside $\mathrm{Re}(\mathrm{Re})$, and notoginsenoside R1 (R1) are typical active ingredients, represented for biological effects of Panax ginseng species such as Ginseng, Pseudoginseng, Vietnamese Ginseng, American Ginseng,... [1-6]. The content of these active ingredients is the basis for determining the quality of ginseng species according to current Pharmacopoeia standards. The published 
health supplement products also use the content of the above active ingredients as quality control criteria [3-6]. However, the Vietnamese Pharmacopoeia has only a separate monograph for the medicinal herbs of Ginseng, Pseudoginseng, and Vietnamese Ginseng, which regulates the determination of the ginsenosides and notoginsenoside R1 content by high-performance liquid chromatography (HPLC). In the US Pharmacopoeia, 43 dietary supplements have quality regulations for Ginseng medicinal powder and Ginseng extract powder, but these regulations are applied for one-ingredient products only. Methods for determination of these compounds in mixed health supplement products which contain Ginseng, Pseudoginseng, and many other medicinal herbs or vitamins, minerals in the form of tablets, powder, liquid... have not been published. Therefore, it is necessary to develop a method that meets the current regulations to determine the content of ginsenosides $\mathrm{Rg} 1, \mathrm{Rb} 1, \mathrm{Re}$, and notoginsenoside $\mathrm{R} 1$ in health supplement samples. The HPLC method with DAD detector has high specificity, accuracy, simplicity, ease of implementation, and popularity, which can be applied in many laboratories that have been selected to carry out this study to analyze and quality control health supplements containing Ginseng and Pseudoginseng in Vietnam market.

\section{MATERIALS AND METHODS}

\subsection{Equipment}

The equipment used in this study has been calibrated according to ISO/IEC 17025 and GLP which include a liquid chromatography system of Shimadzu - LC-2030C 3D Plus with DAD (Shimadzu, Japan), a solid-phase extraction (SPE) system (Supelco, US), an analytical balance, with the accuracy of $0.01 \mathrm{mg}$ (Metler Toledo), and other common laboratory equipment. The chromatography column was InertSustain C18 $(250 \times 4.6 \mathrm{~mm} ; 5 \mu \mathrm{m})$ (GL Sciences, Japan) and the C18 SPE column (6 mL, $500 \mathrm{mg}$ ) (SilactSPE ${ }^{\mathrm{TM}}$ Affinisep, France).

\subsection{Standard materials and chemicals}

The standard materials consist of Notoginsenoside R1 (Lot 19120521, purity of 97.9\%), Ginsenoside Re (Lot 19010322, purity of 98,8\%) from Shanghai Tauto Biotech Co., Ltd., China; and Ginsenoside Rg1 (Lot 0117C002.01, purity of 94.05\%), Ginsenoside Rb1 (Lot 0117C001.01, purity of 88.59\%) from National Institute of Drug Quality Control, Vietnam.

The solvents used for HPLC separation were acetonitrile (ACN) and methanol of HPLC grade, obtained from Merck Vietnam.

\subsection{Samples}

- Sample matrices:

+ Solid sample: Tablet contains Pseudoginseng (100 mg), Ginkgo leaf extract, Blueberry extract, magnesium lactate, citicoline, vitamin B1, vitamin B6, magnesium stearate, methylparaben, propylparaben, polyvinylpyrrolidone (PVP), and talc.

+ Liquid sample: Solution contains Pseudoginseng (2 g/90 mL), Korean jujube, water.

+ Oily sample: soft capsule contains: Pseudoginseng (125 mg), Ginkgo biloba, rutin, gelatin, white beeswax, sorbitol, soybean oil, palm oil, lecithin, and glycerin.

- Spiked samples: Standard solutions were added into sample matrices at specific concentrations. 
- Blank samples: Three corresponding samples were produced according to the research sample formula (solid, liquid, oil) but these samples did not contain Pseudoginseng.

- Real samples: 20 commercial health supplement products containing Ginseng and Pseudoginseng collected from the local markets.

\subsection{Methods}

\subsubsection{Optimization of chromatography conditions}

Refer to some previous studies [3-4] and conditions of our laboratory, we investigated the following conditions: chromatography column, gradient program, flow rate, and injection volume. We selected the optimized conditions that obtain criteria of good separation (resolution greater than 1.5), balance peak shape, no interference of matrix peaks, appropriate pressure, and reasonable analysis time.

\subsubsection{Optimization of sample preparation}

Refer to previous studies [3-6], we investigated two processes of sample preparation: (1) sample was extracted by $70 \%$ methanol, or (2) $90 \%$ methanol, and then cleaned up by solid phase extraction. After that, the temperature of the extraction step was tested. We would select the optimized procedure that has high recovery, and minimum matrix interference.

\subsubsection{Method validation}

Method validation was conducted according to AOAC Appendix $\mathrm{K}$ on solid, liquid, and oily samples with criteria of specificity, limit of detection (LOD), limit of quantitation (LOQ), linear range, and accuracy [7].

\subsubsection{Application}

The developed method was applied to determine the content of R1, Rg1, Re, Rb1 in some commercial health supplements. Each sample was analyzed in triplicate and measured the average.

\section{RESULTS AND DISCUSSION}

\subsection{Optimization of chromatography conditions}

The chromatographic conditions of the Hong Kong Pharmacopoeia [6] were used to investigate the chromatographic column. The mixed standard solutions were analyzed on a C18 Shimadzu column, a C18 InertSustain column, and a C18 Eclipse Plus column $(250 \mathrm{~cm} \times 4.6$ $\mathrm{mm}, 5 \mu \mathrm{m})$. The results of analysis by the C18 InertSustain column showed that the peaks R1, $\mathrm{Rg} 1, \mathrm{Re}, \mathrm{Rb} 1$ separated most clearly, and the resolution of peaks Rg1 and Re was 1.6, which is acceptable. Three mobile phase gradient programs including (1) $\mathrm{ACN}-\mathrm{H}_{2} \mathrm{O}$ gradient in 65 minutes, (2) $\mathrm{ACN}-\mathrm{H}_{2} \mathrm{O}$ gradient in 80 minutes, and (3) $\mathrm{ACN}-\mathrm{H}_{2} \mathrm{O}$ gradient in 100 minutes were investigated. The result showed that the gradient (2) gave the best separation between analytes and interference from the matrix sample. We also examined the flow rate from 1.0 to $2.0 \mathrm{~mL} / \mathrm{min}$, and injection volume from $10-50 \mu \mathrm{L}$.

In conclusion, the optimized conditions included the use of InertSustain C18 $(250 \times 4.6$ $\mathrm{mm}$ i.d.; particle size $5 \mu \mathrm{m}$ ) chromatography column and the mobile phase consisted of ACN and water with gradient program in Table 1 at the flow rate of $1.6 \mathrm{~mL} / \mathrm{min}$. The injection volume 
was $20 \mu \mathrm{L}$. The DAD was used with the wavelength at $203 \mathrm{~nm}$. With these conditions, the chromatogram of the standard solution analyzed was presented in Figure 1.

Table 1. Gradient program

\begin{tabular}{ccc}
\hline Time $($ min $)$ & Acetonitrile $(\%, v / v)$ & Water $(\%, v / v)$ \\
\hline $0-20$ & 20 & 80 \\
$20-40$ & $20 \rightarrow 45$ & $80 \rightarrow 55$ \\
$40-75$ & $45 \rightarrow 55$ & $55 \rightarrow 45$ \\
$75-80$ & 20 & 80 \\
\hline
\end{tabular}

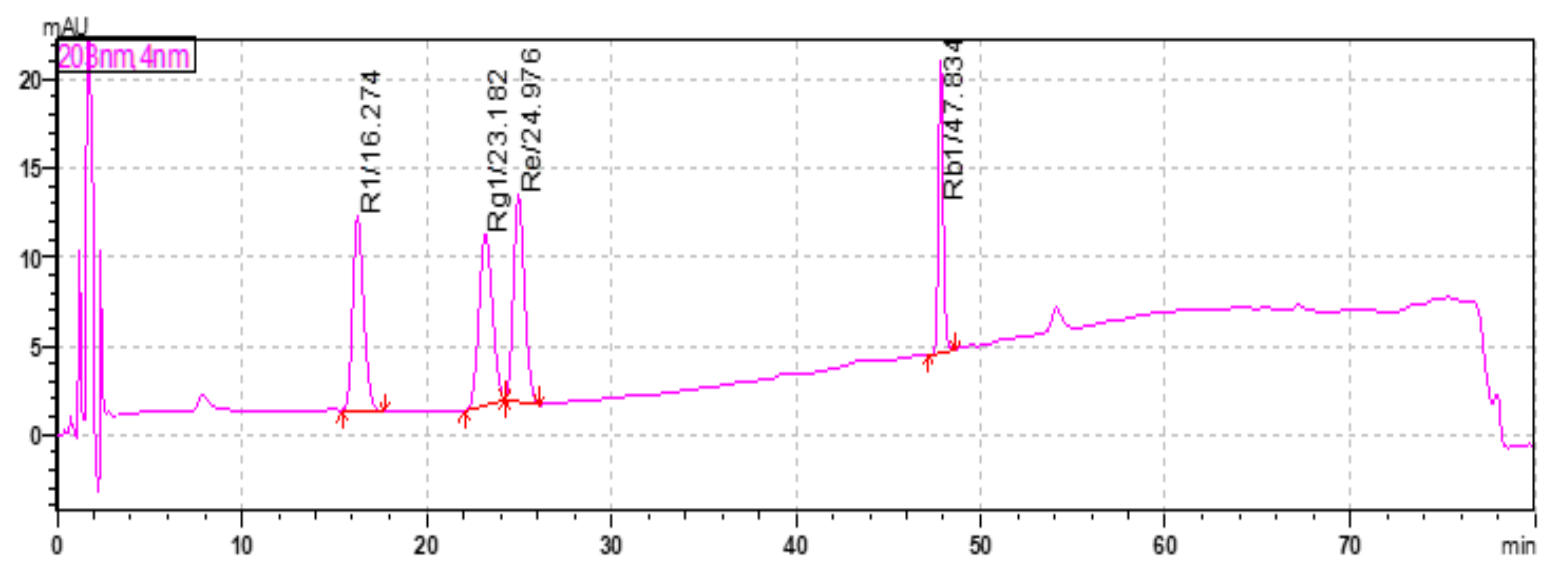

Figure 1. Chromatogram of standard solution analyzed by the optimized conditions

\subsection{Optimization of sample preparation}

\subsubsection{Sample extraction}

Two sample extraction procedures were conducted on the spiked sample (the standard solution was added into the matrix sample so that the final concentration of extraction solution was at $50 \mu \mathrm{g} / \mathrm{mL}$ for each analyte).

- Sample extraction procedure 1:

+ For solid and oily sample: A portion of $2.0 \mathrm{~g}$ sample was weighed into a $50 \mathrm{~mL}$ conical centrifuged tube. Then, the sample was added with $30 \mathrm{~mL}$ of $90 \%$ methanol, vortexed, ultrasonicated at the temperature of $50^{\circ} \mathrm{C}-60^{\circ} \mathrm{C}$ for 30 minutes, centrifuged at $6,000 \mathrm{rpm}$ for five minutes. The extract solution was transferred into a $100 \mathrm{~mL}$ beaker, while the solid residue was re-extracted with $15 \mathrm{~mL}$ of $90 \%$ methanol. The extract solution was collected, and the solvent was evaporated. The residue was resuspended in $5 \mathrm{~mL}$ water. The sample solution was transferred into an SPE column that had already been activated by $3 \mathrm{~mL}$ methanol and $3 \mathrm{~mL}$ water. The column was washed with $5 \mathrm{~mL}$ water, $5 \mathrm{~mL}$ mixture of methanol: water $(3: 7, \mathrm{v} / \mathrm{v})$ at a speed of $2 \mathrm{~mL} / \mathrm{min}$. Analytes were eluted by $8 \mathrm{~mL}$ methanol at $1 \mathrm{~mL} / \mathrm{min}$, the elution was collected into a $10 \mathrm{~mL}$ volumetric flask. Methanol was used to make up the solution to the mark 
of the volumetric flask. The sample solution was shaken well and filtered through a $0.45 \mu \mathrm{m}$ membrane.

+ For liquid sample: A portion of $5.0 \mathrm{~mL}$ sample was cleaned through an SPE column similarly to the above procedure.

- Sample extraction procedure 2:

+ For solid and oily sample: sample was extracted similarly to procedure 1 except that the extraction solvent was 70\% methanol and the sample was not cleaned through an SPE column.

+ For liquid sample: A portion of $5.0 \mathrm{~mL}$ sample was transferred into a $50 \mathrm{~mL}$ flask. Then, the sample was added methanol, ultrasonicated for 30 minutes, cooled down to room temperature, added methanol to reach $50 \mathrm{~mL}$ in total. The solution was filtered through a 0.45 $\mu \mathrm{m}$ membrane.

The blank sample of each matrix was analyzed. Recoveries of two sample preparation procedures were presented in Figure 2.

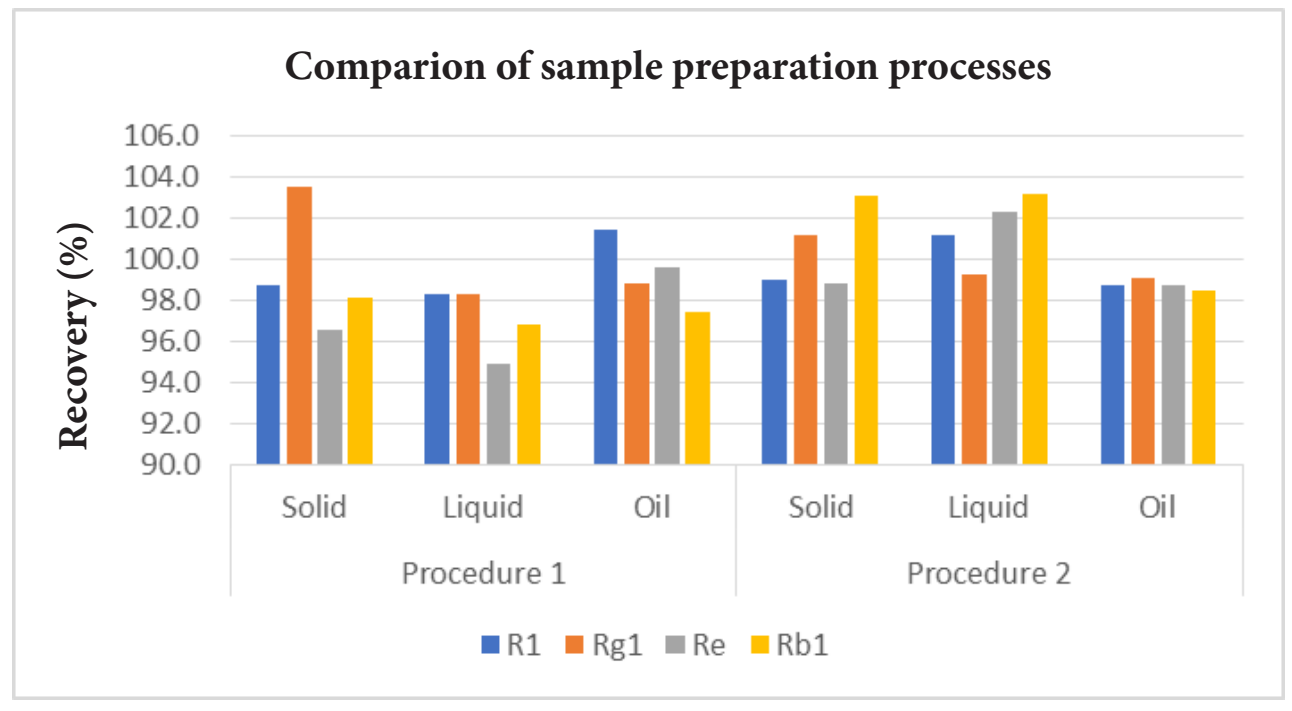

Figure 2. Chart of sample preparation investigation

From Figure 2, it can be seen that recoveries of procedure 2 were higher than that of procedure 1, but they have positive errors in cases of the solid and liquid sample matrix. Due to the complexity of the health supplement matrix and the low content of analytes, the matrix effect hugely affected the analytical results. For procedure 1, the recoveries still met AOAC requirements at the corresponding concentration level. Furthermore, cleaning sample extraction with an SPE column can reduce other substances introduced into the analytical equipment. Therefore, procedure 1 was chosen for further steps of our research.

\subsubsection{Investigation of sample extraction temperature}

Temperature is a factor affecting sample extraction. In this case, the temperature modification can change the solubility of analytes and solvent evaporation. The temperature was investigated in the sample extraction step at $30^{\circ} \mathrm{C}, 40^{\circ} \mathrm{C}, 50^{\circ} \mathrm{C}, 60^{\circ} \mathrm{C}$, and $70^{\circ} \mathrm{C}$; and in the solvent evaporation step at $50^{\circ} \mathrm{C}, 60^{\circ} \mathrm{C}, 70^{\circ} \mathrm{C}, 80^{\circ} \mathrm{C}$, and $90^{\circ} \mathrm{C}$ in the solid sample matrix. The effect of temperature on the extraction capacity was shown in Figure 3. 



Figure 3. Effect of temperature on the extraction capacity

From Figure 3, extraction temperature at $50^{\circ} \mathrm{C}$ and $60^{\circ} \mathrm{C}$ gave the highest signal of analytes. Solvent evaporation temperature at $50^{\circ} \mathrm{C}, 60^{\circ} \mathrm{C}$, and $70^{\circ} \mathrm{C}$ gave the similar signal of analytes; while at $80^{\circ} \mathrm{C}$ and $90^{\circ} \mathrm{C}$, the signal of analytes reduced may due to thermal decomposition. Thus, to enhance sample extraction efficiency, the chosen extraction temperature was $50^{\circ} \mathrm{C}-60^{\circ} \mathrm{C}$, and optimized evaporation temperature was $60^{\circ} \mathrm{C}-70^{\circ} \mathrm{C}$.

\subsubsection{Optimization of SPE cleaning procedure}

Washing the SPE column after loading the sample is an important step of the SPE procedure. The investigation of washing solvent including methanol and water at the rate of $(5: 5, \mathrm{v} / \mathrm{v}),(6: 4, \mathrm{v} / \mathrm{v}),(3: 7, \mathrm{v} / \mathrm{v})$, and $(2: 8, \mathrm{v} / \mathrm{v})$ was conducted in the oily sample matrix spiked at a concentration of $50 \mu \mathrm{g} / \mathrm{mL}$. The results showed that in the case of methanol:water at the rate of $(5: 5, \mathrm{v} / \mathrm{v}),(6: 4, \mathrm{v} / \mathrm{v})$, analytes were lost during the washing column step; at the rate of $(2: 8, \mathrm{v} / \mathrm{v})$, the matrix effect was significant; at the rate of $(3: 7, \mathrm{v} / \mathrm{v})$, the matrix effect was less significant and recoveries were acceptable. Thus, methanol : water $(3: 7, \mathrm{v} / \mathrm{v})$ was chosen as the optimized washing column solvent.

Eluent mainly affects the efficiency of the SPE procedure. Pure methanol, $90 \%$ methanol, and $80 \%$ methanol were investigated. The results showed that pure methanol gave the highest recovery, so it was chosen for the eluent.

\subsection{Method validation}

\subsubsection{Specificity}

Matrix sample, mixed standard solution, and spiked sample were analyzed by the developed method; their chromatograms were shown in Figure 4 and Figure 5.

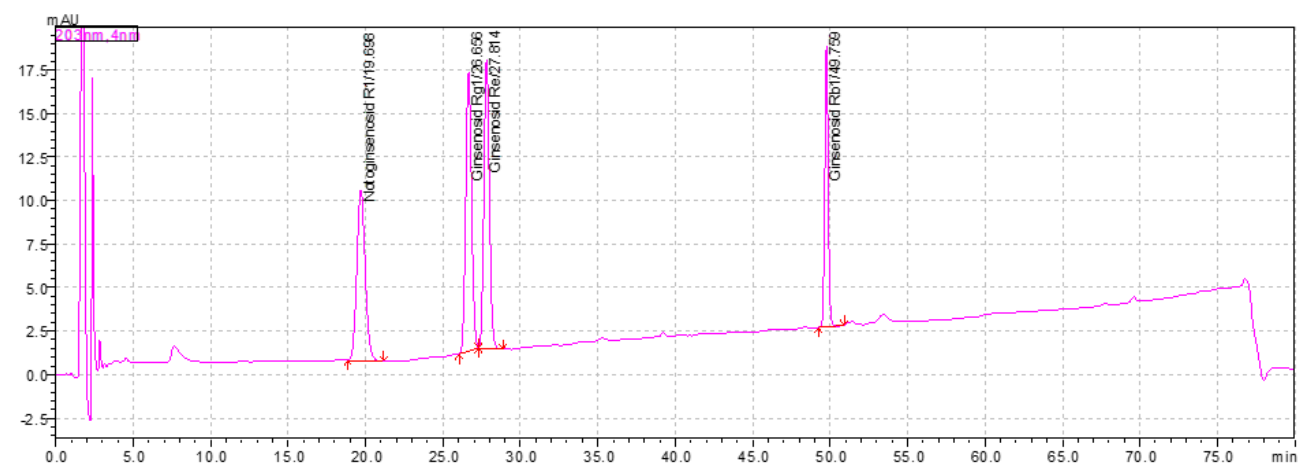

Figure 4. Chromatogram of mixed standard solution 


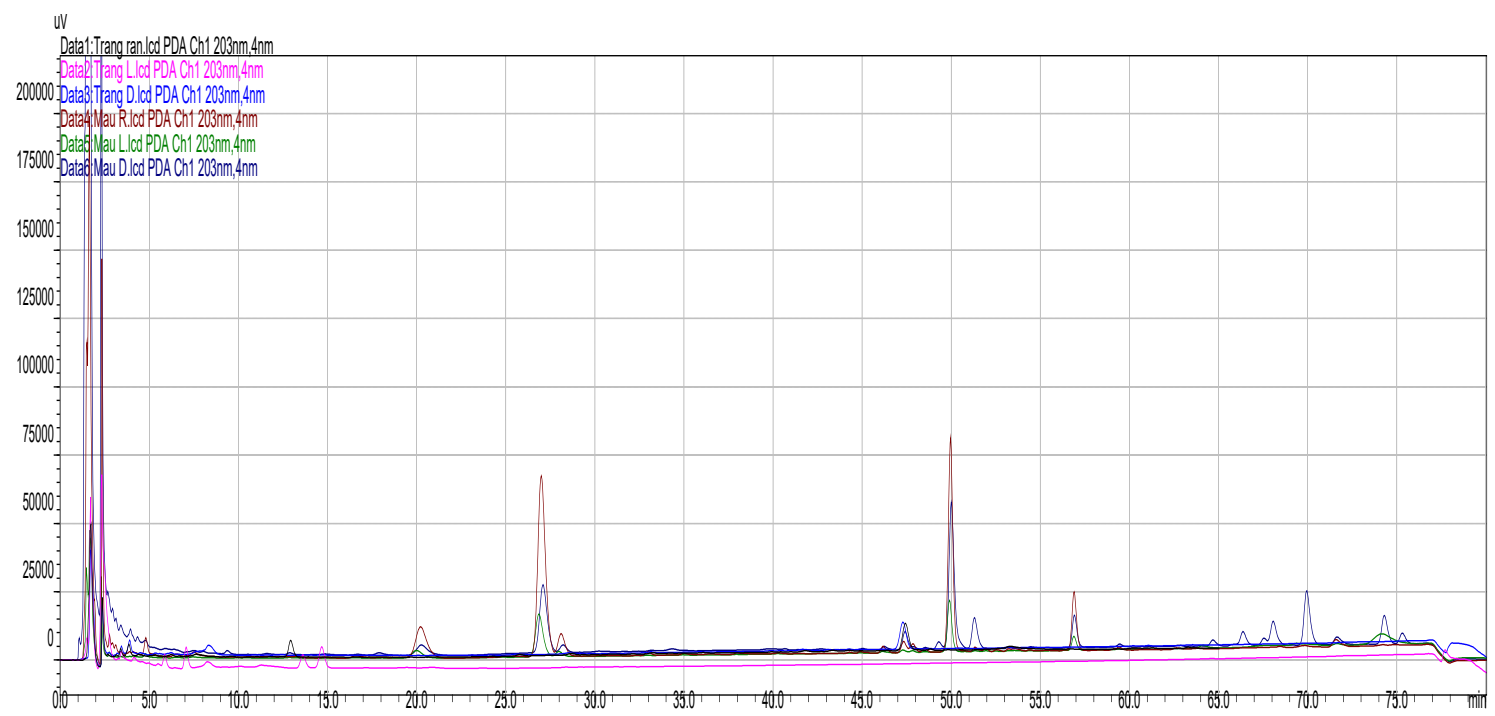

Figure 5. Overlay chromatograms of blank and spiked samples for solid, liquid, and oily matrices

In the chromatogram of the spiked sample, the retention time of analytes agreed with that of the standard solution: R1 (19.7 $\mathrm{min}), \operatorname{Rg} 1$ (26.6 min), Re (27.8 min), and Rb1 (49.7 min). Peaks of analytes in the spiked sample were completely separated from other substances in the matrix. In the blank samples, there were no peaks at the same retention time as the analytes. Therefore, the analytical method has an acceptable specificity with $\mathrm{R} 1, \mathrm{Rg} 1, \mathrm{Re}$, and $\mathrm{Rb} 1$ to identify and quantify these substances in health supplements.

\subsubsection{Calibration curve}

Mixed standard solutions containing R1, Rg1, Re, and Rb1 at the concentration from 4,0 to $400 \mu \mathrm{g} / \mathrm{mL}$ were analyzed. Calibration curves were built by determining the correlation between the concentration of analytes present in the solution and the corresponding peak area obtained on the chromatograms by the linear regression method. The regression was presented in Table 2 .

Table 2. Calibration curves of analytes

\begin{tabular}{ccc}
\hline Analytes & Concentration $(\mu \mathrm{g} / \mathrm{ml})$ & Calibration curve \\
\hline $\boldsymbol{R} \mathbf{1}$ & $3.99-399.43$ & $\mathrm{y}=3,751 \mathrm{x}+1,347 ; \mathrm{R}^{2}=0.9996$ \\
$\boldsymbol{R} \boldsymbol{g} \mathbf{1}$ & $4.06-406.30$ & $\mathrm{y}=4,538 \mathrm{x}-4,847 ; \mathrm{R}^{2}=0.9997$ \\
$\boldsymbol{R} \boldsymbol{}$ & $4.11-411.01$ & $\mathrm{y}=4,156 \mathrm{x}+597 ; \mathrm{R}^{2}=0.9994$ \\
$\boldsymbol{R} \boldsymbol{b} \mathbf{1}$ & $3.97-396.88$ & $\mathrm{y}=2,624 \mathrm{x}+1,361 ; \mathrm{R}^{2}=0.9991$
\end{tabular}

Results in Table 2 showed that in the range of $4-400 \mu \mathrm{g} / \mathrm{mL}$, there were linear regressions between concentration and peak area of analytes with the regression coefficients $\mathrm{R}^{2}$ from 0.9991 to 0.9997 . Deviation values were all within $\pm 15 \%$ and $\pm 20 \%$ at LOQ required by many institutions in the US, Canada, and Europe [7]. Thus, the calibration curves of the analytes were 
satisfactory and accepted under the AOAC International requirements.

\subsubsection{Limit of detection (LOD), limit of quantification (LOQ)}

LOD and LOQ of the developed method were calculated based on the standard deviation of spiked samples. The spiked samples were added standard solutions so that the concentration of each analyte in the final extraction solution was $10 \mu \mathrm{g} / \mathrm{mL}$. These samples were analyzed in six replicates. From that analysis, the average and standard deviation (SD) were calculated. LOD and $\mathrm{LOQ}$ were calculated as $\mathrm{LOD}=3 \mathrm{SD}, \mathrm{LOQ}=10 \mathrm{SD}$. R-value was calculated as $\mathrm{R}=\bar{x} / \mathrm{LOD}$; if the R-value was in the range of 4 to 10 , the concentration of the tested sample was suitable and LOD was believable [8]. LOD and LOQ of the developed method corresponding to each type of samples were presented in Table 3.

Table 3. LOD, LOQ of the developed method

\begin{tabular}{|c|c|c|c|c|c|c|c|}
\hline \multirow{2}{*}{$\begin{array}{l}\text { Ana- } \\
\text { lytes }\end{array}$} & \multicolumn{3}{|c|}{$L O D$} & \multicolumn{3}{|c|}{$L O Q$} & \multirow{2}{*}{ R-value } \\
\hline & $\begin{array}{c}\text { Solid } \\
(\mu g / g)\end{array}$ & $\begin{array}{c}\text { Oily } \\
(\mu g / g)\end{array}$ & $\begin{array}{c}\text { Liquid } \\
(\mu g / m L)\end{array}$ & $\begin{array}{l}\text { Solid } \\
(\mu g / g)\end{array}$ & $\begin{array}{c}\text { Oily } \\
(\mu g / g)\end{array}$ & $\begin{array}{c}\text { Liquid } \\
(\mu g / m L)\end{array}$ & \\
\hline$R 1$ & 6.47 & 5.01 & 2.13 & 21.57 & 16.69 & 7.11 & $7.23-9.34$ \\
\hline$R g 1$ & 6.44 & 6.89 & 2.45 & 21.48 & 22.98 & 8.16 & $7.90-9.16$ \\
\hline$R e$ & 5.34 & 5.34 & 2.77 & 17.79 & 17.79 & 9.22 & $7.05-8.18$ \\
\hline$R b 1$ & 4.93 & 5.76 & 2.42 & 16.44 & 19.20 & 8.05 & $6.77-9.82$ \\
\hline
\end{tabular}

\subsubsection{Accuracy}

The accuracy of the developed method was estimated from the precision and trueness. Real samples of each sample type were analyzed six times for inter-day relative standard deviation $\operatorname{RSD}(n=6)$, and 12 times for intra-day RSD $(n=12)$. The accuracy of the method was evaluated based on the recovery of the spiked sample. The sample matrix was added standard solution so that after sample treatment, analytes have concentrations of about $4 \mu \mathrm{g} / \mathrm{mL}, 50 \mu \mathrm{g} / \mathrm{mL}$, and 400 $\mu \mathrm{g} / \mathrm{mL}$ for each of the three sample forms; each concentration level was analyzed three times. The results were shown in Table 4.

The method had RSD $(n=6)$ from $1.41-2.91 \%$ (requirement $<4 \%)$ and RSD $(n=12)$ from $1.29-4.85 \%$ (requirement $<6 \%$ ), so the method met the requirement of precision. According to AOAC, at a concentration of $4 \mu \mathrm{g} / \mathrm{mL}$ (corresponding to $20 \mu \mathrm{g} / \mathrm{g}$ in solid, oil samples and $8 \mu \mathrm{g} /$ $\mathrm{mL}$ in liquid form), the recovery must reach 85 - 110\%; at $50 \mathrm{~g} / \mathrm{mL}$ (corresponding to $250 \mu \mathrm{g} / \mathrm{g}$ in solid and oily samples and $100 \mu \mathrm{g} / \mathrm{mL}$ in liquid sample), recovery should reach 90 - 108\%; at $400 \mathrm{~g} / \mathrm{mL}$ (corresponding to 2,000 $\mu \mathrm{g} / \mathrm{g}$ in solid and oily sample and $800 \mathrm{~g} / \mathrm{mL}$ in liquid form), the recovery should be 92 - 105\%. Through the results of Table 4, the method was obtained the recovery requirements in the respective concentration range [7]. 
Table 4. Results of accuracy assessment

\begin{tabular}{ccccc}
\hline Sample type & Analytes & $\boldsymbol{R S D}(\boldsymbol{n}=\mathbf{6})(\%)$ & $\boldsymbol{R S D}(\boldsymbol{n}=\mathbf{1 2})(\%)$ & Recovery (\%) \\
\hline \multirow{3}{*}{ Solid } & $\mathrm{R} 1$ & 1.80 & 1.98 & $87.55-100.37$ \\
& $\mathrm{Rg} 1$ & 2.10 & 2.39 & $88.86-103.53$ \\
& $\mathrm{Re}$ & 1.96 & 3.23 & $90.07-96.05$ \\
& $\mathrm{Rb} 1$ & 2.16 & 1.87 & $94.30-98.12$ \\
\cline { 2 - 5 } Oily & $\mathrm{R} 1$ & 1.58 & 2.23 & $88.55-98.29$ \\
& $\mathrm{Rg} 1$ & 1.83 & 1.96 & $93.50-98.33$ \\
& $\mathrm{Re}$ & 1.84 & 2.58 & $87.23-97.32$ \\
& $\mathrm{Rb} 1$ & 1.56 & 2.01 & $91.82-99.40$ \\
\cline { 2 - 4 } & $\mathrm{R} 1$ & 1.41 & 3.47 & $90.39-101.39$ \\
& $\mathrm{Rg} 1$ & 2.12 & 4.04 & $90.70-101.09$ \\
& $\mathrm{Re}$ & 2.91 & 4.85 & $91.00-100.08$ \\
& $\mathrm{Rb} 1$ & 1.94 & 2.71 & $90.70-98.00$ \\
\hline
\end{tabular}

\subsubsection{Results of real samples analysis}

The developed method was applied to analyze 20 real health supplement samples. In which, one sample contained Ginseng and Pseudoginseng, and five other medicinal herbs; nine samples contained Pseudoginseng and at least two other medicinal herbs; ten samples contained Ginseng, vitamines, and some other medicinal herbs. These samples were in form of powder, tablet, soluble nuggets, liquid, drink, soft capsule, and tea bag. The results were shown in Table 5.

Table 5. Results of real samples analysis

\begin{tabular}{|c|c|c|c|c|c|c|c|c|}
\hline \multirow{2}{*}{$\begin{array}{c}\text { Sample } \\
\text { code }\end{array}$} & \multicolumn{4}{|c|}{ Content of analytes $(\mathrm{mg} / \mathrm{g})$} & \multirow{2}{*}{$\begin{array}{c}\text { Sample } \\
\text { code }\end{array}$} & \multicolumn{3}{|c|}{ Content of analytes $(\mathrm{mg} / \mathrm{g})$} \\
\hline & $R 1$ & $\operatorname{Rg} 1$ & $R e$ & $R b 1$ & & $R g 1$ & $R e$ & $R b 1$ \\
\hline M 1 & 0.23 & 0.76 & 0.097 & 0.92 & M 11 & 0.043 & 0.077 & 0.083 \\
\hline M 2 & 0.066 & 0.26 & 0.028 & 0.68 & M 12 & 0.046 & 0.069 & 0.047 \\
\hline M 3 & 0.16 & 0.55 & 0.067 & 0.67 & M 13 & 0.037 & 0.042 & 0.19 \\
\hline M 4 & 0.78 & 2.75 & 0.27 & 2.79 & M 14 & 0.56 & 0.29 & 1.63 \\
\hline M 5 & - & - & - & + & M 15 & 0.049 & 0.18 & 0.23 \\
\hline M 6 & 1.28 & 4.92 & 0.57 & 8.73 & M 16 & 0.039 & 0.015 & 0.024 \\
\hline$M 7$ & 0.13 & 0.84 & 0.18 & 1.18 & M 17 & + & + & 0.048 \\
\hline M 8 & 0.31 & 1.10 & 0.11 & 1.11 & M 18 & 3.20 & 6.83 & 0.99 \\
\hline M 9 & + & + & + & + & M 19 & - & - & - \\
\hline M 10 & 1.57 & 5.86 & 0.55 & 10.29 & M 20 & + & + & + \\
\hline
\end{tabular}

Note: “-”: lower than LOD, “+”: detected but lower than LOQ 
The results of analysis of 20 commercial health supplement samples showed that the concentrations of four research substances in the samples were very different: R1 from 0.066 to $1.57 \mathrm{mg} / \mathrm{g}$ of sample, Rg1 from 0.037 to $5.86 \mathrm{mg} / \mathrm{g}$ sample, Re from 0.015 to $6.92 \mathrm{mg} / \mathrm{g}$ sample, Rb1 from 0.024 to $10.29 \mathrm{mg} / \mathrm{g}$ sample. Even, one sample did not detect R1 (< LOD), two samples did not detect Rg1 and Re (<LOD); some samples (M17, M20, M9) have very low active ingredient content (<LOQ). In particular, samples M5, M9, M19 did not meet the quality requirements according to the product announcement on the label. From that, it is necessary to strengthen the quality control of products announced with Pseudoginseng and Ginseng.

\section{CONCLUSIONS}

The research has developed a method to simultaneously quantify R1, Rg1, Rb1, and Re in health supplements by HPLC-DAD. The method was fully validated and met the requirements of an analytical method according to current AOAC guidelines. The results of applying this method in 20 commercial samples showed that the developed method was appropriate and feasible. The research results can provide laboratories with a reference procedure to save costs when simultaneously quantifying the active ingredients in the health supplements containing Ginseng and Pseudoginseng.

\section{REFERENCES}

[1]. D. T. Loi, Vietnamese medicinal plants and herbs. Hanoi: Medical Publisher, pp.289-290, 804-808, 2006.

[2]. N. T. Hanh, "Research to develop a method to determine some ginsenosides in functional foods containing Panax ginseng," Master of Science Thesis, Hanoi University of Science, Vietnam National University, 2016.

[3]. Ministry of Health, Vietnamese Pharmacopoeia V, vol 2. Hanoi: Medical Publisher, pp. 1279-1280, 1313-1314, 1321-1322, 2017.

[4]. Department of Health Government of the Hong Kong Special Administrative Region, Hong Kong Chinese Materia Medica Standards, vol. 1, pp. 68-77, 80-89, 2005.

[5]. Medicines and Healthcare products Regulatory Agency, British Pharmacopoeia 2020, London: The Stationery Office, pp. 248-251, pp. 361-362, 2019.

[6]. U.S. Pharmacopeia National Formulary, The United States Pharmacopeia USP 43 - NF 38, United Book Press, pp.4774-4775, 2020.

[7]. AOAC - Appendix K: Guidelines for Dietary Supplements and Botanicals - Part I: AOAC Guidelines for Single-Laboratory Validation of Chemical Methods for Dietary Supplements and Botanicals, 2013.

[8]. National Institute for Food Control, Method validation in chemical and microbiological analysis, Sciences and Technology Publisher, pp. 31, 2010. 


\title{
Định lượng đổng thời notoginsenoside R1 và ginsenoside Rg1, Rb1, Re trong thực phẩm bảo vệ sức khỏe bằng HPLC-DAD
}

\author{
Đàm Thị Thu', Nguyễn Thị Kiều Anh ${ }^{2}$, Nguyễn Thị Thanh Phương \\ Nguyễn Thị Hồng Hạnh ${ }^{1}$, Nguyễn Thành Đạt ${ }^{1}$ \\ ${ }^{1}$ Trung tâm Kiểm nghiệm thuốc, mỹ phẩm, thực phẩm Hà Nội, Việt Nam \\ ${ }^{2}$ Trường Đại học Dược Hà Nội, Việt Nam
}

Tóm tắt

Nghiên cứu đã tối ưu hóa phương pháp định lượng đồng thời notoginsenoside R1, ginsenoside Rg1, ginsenoside Re, ginsenoside Rb1 trong chế phẩm thực phẩm bảo vệ sức khỏe dạng rắn, lỏng, dâu bằng sắc ký lỏng hiệu năng cao (HPLC-DAD) kết hợp kỹ thuật chiết pha rắn (SPE). Các chất phân tích được tách bằng cột InertSustain $\mathrm{C} 18(250 \times 4,6 \mathrm{~mm} ; 5 \mu \mathrm{m})$ với chương trình rửa giải gradient dung môi gồm acetonitril và nước. Các chất phân tích tuyến tính trong khoảng từ 4,0 - $400 \mu \mathrm{g} / \mathrm{mL}$, với hệ số $\mathrm{R}^{2}$ đều lớn hơn 0,999 . Phương pháp cho giới hạn phát hiện và giới hạn định lượng lần lượt nằm trong khoảng $2,13-6,89 \mu \mathrm{g} / \mathrm{g}$ chế phẩm và 7,11 - 22,98 $\mu \mathrm{g} / \mathrm{g}$ chế phẩm. Độ thu hồi của bốn chất phân tích nằm trong khoảng từ 87,2 - 103,5\%. Độ chụm với độ lệch chuẩn tương đối lặp lại trong ngày là $1,41-2,91 \%$ và độ lệch chuẩn tương đối khác ngày là 1,87 - 4,85\% đáp ứng yêu câu của AOAC. Phương pháp đã được ứng dụng để xác định hàm lượng các chất phân tích trong 20 mẫu thực phẩm bảo vệ sức khỏe chứa Nhân sâm, Tam thất.

Tư khóa: notoginsenoside R1, ginsenoside Rg1, ginsenoside Re, ginsenoside Rb1, TPBVSK, HPLC. 